\title{
Recuperación de la crónica de Cortes durante la Transición democrática: los Apuntes parlamentarios de Víctor Márquez Reviriego
}

\author{
José Romero PortiLlo \\ Universidad de Sevilla \\ jromero11@us.es
}

Recibido: 26 de junio de 2013

Aceptado: 19 de noviembre de 2013

\section{Resumen}

Publicados en la revista Triunfo entre 1977 y 1981, los ‘Apuntes parlamentarios' de Víctor Márquez Reviriego constituyeron un testimonio de especial relieve para conocer el desarrollo de las recién estrenadas Cortes democráticas en España. Tras cuarenta años de dictadura, este periodista, junto a otros compañeros de profesión, retomó la crónica parlamentaria, una modalidad periodística que permanecía olvidada en las hemerotecas, a pesar de haber contado con notable prestigio en la prensa española desde el siglo XIX. Autores como Andrés Borrego, Azorín, Wenceslao Fernández Flórez o Josep Pla habían destacado anteriormente en esta parcela del periodismo, que combina la precisión informativa y la creatividad literaria. Este artículo describe la aportación de Víctor Márquez Reviriego al revival de la crónica parlamentaria, al tiempo que analiza los principales temas abordados en su obra.

Palabras clave: Víctor Márquez Reviriego, crónica parlamentaria, periodismo político, Transición democrática

\section{Recovery of parliamentary chronicle during the Spanish Democratic Transition: the chronicles of Victor Marquez Reviriego}

\begin{abstract}
Published in the magazine Triunfo between 1977 and 1981, the 'Apuntes parlamentarios' of Víctor Márquez Reviriego were a testimony of particular importance for the development of democratic Cortes recently premiered in Spain. After forty years of dictatorship, this journalist, along with other colleagues, resumed parliamentary chronicle a journalistic mode remained forgotten in libraries, despite having enjoyed considerable prestige in the Spanish press since the nineteenth century. Authors like Andrés Borrego, Azorín, Wenceslao Fernández Flórez or Josep Pla had highlighted earlier in this piece of journalism, combining the accuracy of information and literary creativity. This article describes the contribution of Victor Marquez Reviriego the revival of parliamentary chronicle, while analyzing the main stylistic features of his work.
\end{abstract}

Keywords: Víctor Márquez Reviriego; parliamentary chronicle; political journalism; Spanish Democratic Transition.

\section{Referencia normalizada}

ROMERO PORTILLO, José (2014): "Recuperación de la crónica de Cortes durante la Transición democrática: los Apuntes parlamentarios de Víctor Márquez Reviriego". Estudios sobre el Mensaje Periodístico. Vol. 20, Núm. 1 (enero-junio), págs.: 523-538. Madrid, Servicio de Publicaciones de la Universidad Complutense.

Sumario: 1. Introducción. 2. Fuentes y metodología. 3. El revival del periodismo parlamentario durante la Transición. 4. Los Apuntes parlamentarios de Víctor Márquez Reviriego; 4.1. La tentación canovista; 4.2. El pecado consensual; 4.3. Escaños de penitencia; 4.4. La ruptura del consenso; 4.5. Epílogo: el golpe de Estado del 23-F. 5. Conclusiones. 6. Referencias bibliográficas. 


\section{Introducción}

El Parlamento ha sido un referente informativo ineludible para los medios de comunicación en España desde 1810, año en el que las Cortes de Cádiz establecieron un régimen representativo basado en el principio de soberanía nacional. A partir de esa fecha, Parlamento y periodismo permanecen unidos como las dos caras de una misma moneda o, dicho de otro modo, como contrapesos necesarios en la balanza política. Como señala Forneas Fernández (2004: 191), "el Parlamento sin la Prensa funcionaría sin publicidad y sus iniciativas, sus debates carecerían de la necesaria resonancia (los ciudadanos oyen con los oídos y ven con los ojos de los representantes de la tribuna de la Prensa y, por otra parte, los ojos de los diputados son muy pocos para ver todo lo que ocurre en el país y necesitan que les ayuden los ojos de los periodistas)".

El binomio parlamentarismo-publicidad, o parlamentarismo-periodismo, es una conquista de las revoluciones burguesas, que acabaron con el secretismo y el estricto control de las Cortes del Antiguo Régimen. La idea de que las deliberaciones y los acuerdos adoptados en una asamblea habían de ser públicos, como apunta Durán López (2007), "parte del concepto ilustrado y liberal del Estado, dentro del nuevo valor otorgado a la publicidad (entendida a la manera de Habermas) como eje de la vida colectiva de los ciudadanos". A raíz de ese logro liberal, la prensa amplía sus funciones en el entramado institucional: primero, como mediadora entre la sociedad y el Gobierno; segundo, como informadora de los trabajos realizados en el Parlamento; y tercero, como formadora de la opinión pública, al desempeñar un papel esencial en el desarrollo democrático y en la "educación política" de la ciudadanía.

A estos cometidos de mediar, informar e instruir se une, con el paso de los años, otra función para los periodistas que es la de interpretar las sesiones parlamentarias más allá de la versión oficial aportada por el Periódico de las Cortes, conocido también como Diario de Sesiones. En esta publicación -surgida en octubre de 1810, a los pocos días de la inauguración de las Cortes Generales y Extraordinarias, y dirigida en su primera fase por Bartolomé José Gallardo- aparecen transcritos todos los discursos pronunciados en el Parlamento, las réplicas de los diputados, los resultados de las votaciones y breves anotaciones circunstanciales -aplausos, protestas de sus señorías, etcétera-. Sin embargo, "la descripción de las sesiones, el relato de los incidentes que en ellas se producen, no forman parte de su cometido" (Carandell, 2003. 349). El Diario de Sesiones se aparta del análisis y la descripción del ambiente parlamentario, no se detiene a contextualizar ni a establecer precedentes, no repara en las motivaciones que llevaron a un diputado a intervenir de determinada forma ni atiende a las consecuencias que podrían acarrear las medidas tomadas. Es un órgano aséptico, que carece de la profundidad y la viveza que puede ofrecer un periodista que ha sido testigo de los acontecimientos.

Como reverso del Diario de Sesiones se ajusta la tarea del cronista parlamentario, que suma a su formación política, histórica y cultural una cierta sensibilidad para observar, informar, reflexionar y dar colorido a las sesiones. A diferencia del informador parlamentario o del periodista político, "fiel relator de hechos", el cronista de Cortes es, según Peña González (2001: 134), "un pintor capaz de transmitir a sus lectores el cuadro perfecto para que éstos se hagan la idea más completa de la situación. No basta 
con recoger lo que se dice en un lugar concreto -la sede parlamentaria- sino que además tenemos que saber quién lo ha dicho, cómo lo dice y cómo ha sido recogido por sus compañeros de partido y por sus adversarios, cuál era la temperatura política de la Cámara, qué incidencias se han ido produciendo a lo largo de una exposición, y en unas breves pinceladas trazar ese cuadro de la situación que permita al lector conocer con todo lujo de detalles lo que está pasando".

La crónica es, en apreciación de Gil González (2004:11), "la estampa del tiempo en letra impresa", un relato que "reconstruye la realidad, trozo a trozo, fragmento a fragmento, ordenando y desordenando el tempo de los acontecimientos, erigiéndose en testimonio directo de una época". Pero, además de ser un género periodístico e histórico, la crónica, en su especialidad parlamentaria, contiene rasgos literarios que trascienden la función referencial del lenguaje para adoptar recursos estéticos, como la ficcionalización, la analogía y el simbolismo. A decir de Susana Rotker (2005: 173), en la crónica se produce una "poetización de lo real"; fenómeno que se materializa, por ejemplo, en la obra de autores como Mariano José de Larra, Andrés Borrego, Benito Pérez Galdós, Azorín, Wenceslao Fernández Flórez, Julio Camba, Josefina Carabias o Josep Pla, que combinaron en sus escritos parlamentarios la información con la creación literaria.

Cuando en julio de 1977, un grupo de periodistas -entre los que se encontraba el onubense Víctor Márquez Reviriego-, accede por primera vez a las remozadas Cortes de la democracia, el parlamentarismo contaba con una larga tradición en España, marcada por los claroscuros: por los periodos luminosos en los que brilló una oratoria culta y florida, y por los paréntesis sombríos en los que ni siquiera existió discusión acerca de los asuntos públicos. Precisamente, en el momento en que Víctor Márquez, como cronista acreditado de la revista Triunfo, comienza a escribir sobre el Congreso de los Diputados y el Senado, España se encuentra en un proceso de superación de uno de esos paréntesis, el impuesto por el franquismo, que durante cuatro décadas prohibió la asociación política y la confrontación de ideas. Por lo cual, cuando este periodista traspasa las puertas del Palacio de las Cortes, en la madrileña Carrera de San Jerónimo, está repitiendo una acción recurrente en la historia de los medios de comunicación españoles, la de volver a empezar un camino hacia la libertad de expresión; al tiempo que está recuperando una modalidad periodística, como la crónica parlamentaria, que había permanecido en desuso durante la dictadura, debido a la censura.

Con ánimo informativo y crítico, Víctor Márquez Reviriego compone durante cuatro años -los que transcurren entre 1977 y 1981- un retrato de las Cortes de la Transición, que sirve para que el lector conozca con detalle las circunstancias que giran en torno al hecho parlamentario. Las crónicas de Víctor Márquez, publicadas en Triunfo bajo el título genérico de 'Apuntes parlamentarios', suponen un importante hito en su dilatada trayectoria profesional, que se extiende por numerosas cabeceras -entre ellas, el mencionado semanario Triunfo, Tiempo, Cambio 16, Diario 16, El País, Tribuna, $A B C$, El Mundo, etcétera- desde 1962 hasta principios del siglo XXI. Su trabajo como revitalizador de la crónica parlamentaria es reconocido por compañeros de profesión, entre los que se hallan Carandell (2000: 315), que lo distinguió como "el cronista de la Transición”, o Haro Tecglen (1980: 122), que lo definió como "un representante de 
la sociedad en el Parlamento"; así como por historiadores, como Becarud (1981: 144) o Cuenca Toribio (1995: 461), que dedicaron reseñas a su obra; o bien, por el catedrático de Filología Luis Gómez Canseco (2008: 13), quien en la laudatio que tributa a Víctor Márquez, al ser distinguido éste como doctor honoris causa por la Universidad de Huelva, destacó igualmente su aportación al periodismo de Cortes.

Con sus 'Apuntes parlamentarios' -posteriormente, editados en varios volúmenes-, Víctor Márquez se convierte en un testigo privilegiado de la evolución política de España, pues asiste a momentos de gran trascendencia para el futuro del país, como la promulgación de la Constitución en 1978, la abolición de la pena de muerte, la aprobación de la Ley de Amnistía, la configuración del Estado de las Autonomías o la reforma del sistema fiscal. Más allá de ser un simple mensajero, el periodista expone en sus crónicas diversas reflexiones, analiza los discursos políticos y emite juicios que sirven a los lectores para formarse sus propias opiniones en torno al devenir parlamentario; al tiempo que describe la institución parlamentaria, la personalidad de diputados y senadores, sus ademanes, sus indumentarias o sus hábitos. Aquellos aspectos que, a decir de Azorín (1968: 31), parecen deleznables, bagatelas transitorias y efímeras, de las cuales "no se ocupan los historiadores", son también objeto de sus crónicas.

Recordar el papel desempeñado por los cronistas parlamentarios, entre los que se encuentra Víctor Márquez Reviriego, significa investigar no sólo en torno a una obra periodística concreta, sino también reflexionar acerca de una modalidad periodística que ha perdido presencia en los medios de comunicación. El desplazamiento del poder legislativo hacia el ejecutivo, el desinterés de la ciudadanía por las sesiones parlamentarias, la precariedad laboral del periodismo o la espectacularización informativa son algunos de los factores que han motivado la pérdida paulatina de la crónica de Cortes en las páginas de los diarios o en espacios de radio o televisión. En este sentido, los 'Apuntes parlamentarios' de Víctor Márquez merecen, asimismo, especial atención, por tratarse de una de las últimas manifestaciones regulares de esta modalidad periodística en la prensa española de finales del siglo XX.

\section{Fuentes y metodología}

Este artículo parte de la hipótesis de considerar los 'Apuntes parlamentarios', publicados por Víctor Márquez Reviriego en la revista Triunfo, como un ejemplo de la recuperación y la renovación estilística que experimenta la crónica de Cortes durante la Transición democrática. Para demostrar esta idea, hemos acudido a múltiples fuentes, entre las que sobresale, como es obvio, la producción completa de crónicas parlamentarias firmadas por el autor onubense entre septiembre de 1977 y marzo de 1981. En total, se trata de 112 trabajos periodísticos, que aparecen recogidos en el semanario Triunfo -alojado, desde 2006, en la página web www.triunfodigital.com- y en los libros La tentación canovista (1978), El pecado consensual (1979), Escaños de penitencia (1981) y Apuntes parlamentarios, editado por el Servicio de Publicaciones del Congreso de los Diputados en dos ocasiones, en 1997 y 2001. Para llevar a cabo esta investigación, nos hemos basado principalmente en la última de esas ediciones, pues en ella se incluyen todas las crónicas del periodista y se corrigen muchas de las erratas que aparecieron en los textos originales de Triunfo. 
Asimismo, pueden considerarse como fuentes secundarias de este artículo los estudios parciales que se han realizado en torno a la obra de Víctor Márquez -como son los ensayos de Becarud (1981) y Cuenca Toribio (1995)-, las reseñas publicadas en prensa o en revistas científicas -como es el caso de los textos firmados por Haro Tecglen (1980), Umbral (1982), Tamames (1997), Gómez Marín (2006) o Forneas Fernández (2004)- y la aportación de otros autores a la crónica parlamentaria -Pérez Galdós (1923), Azorín (1968), Fernández Flórez (1950), Pla (2006), Vicent (1984), Carandell (1998)-, cuyos textos han servido para realizar una proyección histórica de este subgénero periodístico.

En cuanto a la metodología, debemos indicar que esta investigación se basa en el análisis cronológico de los ‘Apuntes parlamentarios' de Víctor Márquez Reviriego, dividido en cinco etapas, que se corresponden con los años que el periodista dedica a la información de Cortes. En cada uno de esos periodos, se describe la labor de Márquez Reviriego como cronista, al tiempo que se identifican los temas abordados en sus 'Apuntes', sus principales recursos narrativos y el contexto político, social y económico que rodeaban a dichos escritos.

\section{El revival de la crónica parlamentaria durante la Transición}

La muerte de Franco y la apertura de las Cortes democráticas fueron los acontecimientos decisivos que permitieron el descubrimiento del Parlamento como una nueva ventana informativa para la prensa española. Durante la Transición, el Congreso de los Diputados y el Senado acogieron a periodistas procedentes de diversos medios de comunicación, que se convirtieron en intermediarios entre los políticos y la ciudadanía. En buena medida, los periodistas contribuyeron a fortalecer el consenso pactado a nivel político, ejerciendo no sólo de "correas de transmisión" entre las Cámaras y la opinión pública, sino también interviniendo como críticos de la nueva realidad nacional.

"Con la elección de 1977 de las primeras Cortes democráticas la prensa iba a dejar de ser ese Parlamento de papel que, a falta de instituciones verdaderamente representativas, había servido de tribuna de opinión y caja de resonancia de la vida política española. Las Cortes y los partidos políticos empezarían a cumplir, de esta forma, el papel de representación e intermediación entre la sociedad y el poder que hasta entonces habían desempeñado provisionalmente los medios de comunicación. Ahora eran éstos los que tenían que abrir un espacio a la crónica y al análisis de la actividad parlamentaria, viejo y prestigioso género periodístico recuperado a partir de 1977 y al que distintos periódicos y semanarios dedicaron algunos de sus mejores redactores -caso, por ejemplo, de Manuel Vicent en El País y de Márquez Reviriego en Triunfo-" (Fuentes Aragonés y Fernández Sebastián, 1998: 322).

El periodo histórico que comprende desde el inicio de la Legislatura Constituyente, en 1977, hasta la convocatoria de elecciones generales en 1982 puede calificarse, a grandes rasgos, como una etapa de agitada producción informativa en el Parlamento. El ritmo de las comisiones, debates y plenos celebrados, sobre todo en el Congreso de los Diputados, hicieron de esta institución el centro de todas las miradas, ya fueran políticas o periodísticas; más si cabe por el calado y la importancia de las leyes tramitadas en estos años. 
Esta época se convierte en el momento propicio para el revival de un género periodístico como la crónica parlamentaria (Cuenca Toribio, 1995: 448). Gracias a la aportación de firmas ya habituales en la prensa española-como las de Víctor Márquez Reviriego, Luis Carandell, Manuel Vicent, Cándido, Miguel Ángel Aguilar, José Oneto o Francisco Cerecedo-, las sesiones celebradas en el Congreso y en el Senado ocuparon un lugar central en diarios y revistas de gran tirada. En este periodo, además, las mujeres periodistas accedieron, sin ningún tipo de obstáculo, a la tribuna de prensa del Congreso, como ponen de manifiesto un buen número de autoras - citadas por Menéndez Gijón y Fernández López-Monís, 2004-, que van desde Soledad Gallego-Díaz hasta Julia Navarro, pasando por Susana Olmo, Amalia Sánchez Sampedro, María Antonia Iglesias, Pilar Cernuda, Pilar Narvión o Pilar Urbano, quienes recogieron el testigo de Josefina Carabias, también presente en esta nueva etapa como articulista del diario $\mathrm{Ya}$.

Las Cortes democráticas pasaron en pocos meses de ser un lugar desconocido para los españoles a transformarse en un escaparate llamativo para todo tipo de periodistas y escritores, que retrataban los debates con mayor o menor acierto. Por lo general, en estas nuevas crónicas parlamentarias publicadas tras la muerte de Franco se observa un avance en el estilo discursivo tanto de parlamentarios como de periodistas. Los oradores abandonaron el discurso florido, pausado y retórico de épocas anteriores, heredero aún de las dos grandes escuelas parlamentarias de la II República, la de Alcalá-Zamora y la de Manuel Azaña, como advirtió Francisco Ayala (1985: 11); y se adaptaron, al igual que los informadores, a unos nuevos tiempos en los que dominaba el lenguaje administrativo, cargado de "transferencias del estilo burocrático" (Núñez Ladevéze, 1999: 126).

Poco a poco, las sesiones se fueron amoldando a un reglamento -restrictivo en los turnos de palabra- y a un protocolo mucho más ágil, gracias, entre otras cosas, al sistema de votación electrónico. La división de los grupos parlamentarios y el control interno de éstos repercutirían en un progresivo individualismo en las intervenciones, en el liderazgo de secretarios generales y portavoces, que acallaban las opiniones de otros compañeros de partido -denominados "culiparlantes" por Víctor Márquez-. Estos factores condicionaron la labor del cronista de Cortes y provocaron el sopor de muchos de éstos, que pronto dejarían sus puestos en la tribuna de prensa.

Sin embargo, el hecho que desencadenó el abandono de un buen número de cronistas fue la victoria del PSOE por mayoría absoluta en las elecciones de 1982. Con un dominio evidente de los socialistas en el hemiciclo, muchos debates carecieron del atractivo público que antes generaban. Las principales leyes eran votadas sin margen para la sorpresa, lo cual restaba interés a los medios de comunicación, que comenzaron a explorar nuevas vías de información parlamentaria. Desde esas fechas, se popularizó el llamado "periodismo de pasillos" o "periodismo de declaraciones" en el Parlamento, potenciado por factores como la proliferación de gabinetes de comunicación e intermediarios en la información, la irrupción de las televisiones en un contexto mediático relativamente poblado o la importancia, en consecuencia, de "lo audiovisual" en el panorama de la comunicación (Vázquez Bermúdez, 2005). En cambio, la crónica, que se caracteriza por combinar datos y análisis, perdió "prestigio" a 
favor de una información directa, de testimonio, mucho más demandada, a pesar de ser fugaz y carente de contexto.

Así pues, la crónica parlamentaria experimentó, en apenas una década, una etapa de recuperación y apogeo -paralela a la Transición-, y un rápido desplome, justo cuando empezaron a asentarse las bases del sistema democrático. Probablemente, nunca antes en la historia del periodismo español se habían reunido tantos informadores en la tribuna de prensa de las Cortes como a partir de 1977. Esta eclosión periodística alumbraba un camino ilusionante para el género de la crónica parlamentaria, que, paradójicamente, se apagaría en pocos años, dadas las circunstancias venideras.

\section{Los Apuntes parlamentarios de Víctor Márquez Reviriego}

\subsection{La tentación canovista}

La primera etapa de Víctor Márquez como cronista parlamentario está marcada por la novedad que supone su tarea periodística. Tras casi cuarenta años de dictadura, el Palacio de las Cortes españolas abría sus puertas el 13 de julio de 1977 con un aire renovado, con un funcionamiento totalmente distinto al que se había desarrollado durante las Cortes orgánicas del franquismo. Las elecciones generales celebradas un mes antes habían configurado un sistema político heterogéneo y abierto, donde las distintas opciones ideológicas tenían cabida, gracias a la soberanía nacional. Por tanto, las dos Cámaras representativas de España, el Congreso de los Diputados y el Senado, aparecían como lugares ajenos a la experiencia de un gran número de ciudadanos que no habían vivido otro régimen que el dictatorial. A excepción de aquellas personas que pudieron conocer las Cortes de la II República, la mayor parte de los españoles no tenía una mínima instrucción sobre los mecanismos de la democracia.

Este factor condicionaría en gran medida la labor de Víctor Márquez como cronista de Cortes. Al igual que el resto de los periodistas destinados al Congreso o al Senado, Víctor Márquez tendría que iniciar en 1977 una fase de aprendizaje parlamentario a marchas forzadas, sobre el terreno y, a veces, a un ritmo trepidante, pues determinadas leyes urgían ser aprobadas. El periodista onubense supo solventar este cometido acudiendo a las fuentes históricas, leyendo antiguos ejemplares del Diario de Sesiones y tomando notas sobre los rasgos de la oratoria de la II República. Pero, aun así, este apoyo documental no fue suficiente para afrontar su tarea como cronista de Cortes. Sólo el día a día, el contacto directo con el Congreso y sus protagonistas, los diputados, le serviría para adquirir experiencia y solidez como "apuntador" o "crítico" de las sesiones parlamentarias.

Como destaca Cuenca Toribio (1995: 456), uno de los rasgos más sorprendentes que se observan en este primer periodo de Víctor Márquez es su "rápida instrucción" en las cuestiones debatidas, su resuelta aclimatación a un Parlamento que había permanecido infranqueable durante casi medio siglo. Su amplio bagaje cultural y su formación en Ciencias Políticas -licenciatura que completó en 1962- fueron sus principales bazas para lograr este objetivo. Al contrario de lo que se pudiera pensar en el caso de un periodista neófito, que no ha desempeñado nunca una función tan específica, Víctor Márquez encontró acomodo instantáneo en su nuevo puesto de trabajo. Gracias a la información y los consejos prestados por algunos políticos, como fue el 
caso de Carlos Ollero, se familiarizó velozmente con el Palacio de las Cortes, que consideró su "segunda casa" (Márquez Reviriego, 2001: 12).

Desde la tribuna de prensa, Víctor Márquez asistiría a unas primeras sesiones en las Cortes cargadas de propuestas legislativas y votaciones destinadas a reformar la estructura del régimen franquista. Entre los principales asuntos recogidos por el cronista onubense durante 1977 se encuentran la configuración de la Mesa presidencial del Congreso -"La tentación canovista", 23-VII-1977-, la Ley de Relaciones Gobierno-Parlamento -"El pleno de los poetas", 15-X-1977; "La Cámara de los ecos", 19XI-1977-, la Ley de Amnistía -"La conciencia de España", 22-X-1977-, el inicio de los trámites constitucionales -"Los hijos del Anticristo", 26-XI-1977-, la incorporación a la OTAN y al Mercado Común -"El círculo de lectores", 1-X-1977-, la Ley de Reforma Fiscal y los 'Pactos de la Moncloa' -“A la sombra de Hölderlin”, 5-XI-1977- o la dureza empleada por las fuerzas de orden público -"El pleno del Congreso eucarístico", 24-IX-1977; "La locura de todos", 31-XII-1977-.

Con estos trabajos, el periodista onubense inauguraba el curso parlamentario, un año marcado por la novedad y la inexperiencia de diputados y senadores, pero también por la tendencia que iba a tomar la política española. Una senda dirigida a la bipolarización ideológica y partidista, encarnada en un nuevo "canovismo", ahora representado por UCD y PSOE, o lo que es lo mismo, por Adolfo Suárez y Felipe González. Víctor Márquez alertaba sobre esta situación justo desde la primera crónica parlamentaria realizada para Triunfo. El devenir de los hechos políticos confirmaría dicha actitud, que aparece expresada de forma general en el libro La tentación canovista. Esta obra recibiría elogios y comentarios críticos, como los de Becarud (1981) o Cuenca Toribio (1995: 456-457), quien vio en estas crónicas un elemento indispensable para entender los primeros pasos del parlamentarismo español tras la dictadura, marcados por el "personalismo" de los principales líderes políticos y el monopolio ejercido por los dos grupos mayoritarios en el Congreso.

\subsection{El pecado consensual}

Seis meses después de la apertura de las Cortes democráticas, Víctor Márquez había alcanzado suficiente notoriedad y soltura como cronista de Triunfo. El director de esta revista, José Ángel Ezcurra, mantuvo sus 'Apuntes parlamentarios' como una sección fija en el semanario, al considerarlo como uno de los puntales principales del semanario. No en vano, Ezcurra (1995: 503) había nombrado en 1970 a Víctor Márquez, junto a César Alonso de los Ríos, redactor-jefe del semanario. Una vez recogidos los primeros pasos de las nuevas Cámaras, Víctor Márquez tenía ante sí, en 1978, la responsabilidad de trasladar a los lectores el día a día de un Parlamento que ultimaba la Constitución, el ansiado marco jurídico, que atravesó por múltiples vicisitudes desde su primer día de comisión -“Asignatura pendiente", 13-V-1978-. Entraban en juego entonces posiciones enfrentadas, que iban desde la defensa de la monarquía o la república -"Sorpresas y asombros", 20-V-1978- hasta la discusión sobre el sistema de representación electoral -"El fantasma canovista", 10-VI-1978-. Los debates, que se esperaban mucho más ágiles, provocaron por momentos el cansancio de la ciudadanía y de los medios de comunicación. En una de sus crónicas, titulada "El trote borri- 
quero" (27-V-1978), Víctor Márquez hacía alarde irónico de ese ritmo pausado que caracterizaba a la comisión constitucional.

Víctor Márquez fue testigo en 1978 de la doble senda política abierta en la política española: por un lado, la vía del consenso y la negociación llevada a cabo por los dos partidos mayoritarios -fraguado, sobre todo, por Fernando Abril Martorell, de UCD, y Alfonso Guerra, del PSOE-; y por otro, el alejamiento progresivo de los ciudadanos en los asuntos públicos. La Constitución, que debía ser el hito central de la Transición española, acabó convirtiéndose en el primer eslabón del desencuentro entre la clase política y la sociedad. El secretismo y las cautelas que mantuvieron en la subcomisión encargada de redactarla generaron, primero, el desconocimiento de los contenidos; mientras que los arduos trámites en las comisiones y las largas sesiones para la aprobación en el Congreso y el Senado provocaron un cierto agotamiento (Tusell, 2004: 519).

Por encima del interés que despertaban las novedades del proceso constitucional, a lo largo de 1978 se observa en el cronista una actitud de mayor responsabilidad ante el trabajo que realizaba. Como testigo de las Cortes constituyentes, intenta transmitir toda la información posible de los debates planteados en las Cámaras. Desde el punto de vista discursivo, se podría afirmar que las crónicas de El pecado consensual son las más referenciales de todas cuantas escribió Víctor Márquez. En ellas, informa y analiza a un mismo tiempo las decisiones adoptadas por los grupos parlamentarios, siempre con el deseo de despertar el interés general y acercar los artículos constitucionales a los lectores. Aunque la anécdota, la descripción de ambientes, la etopeya o el comentario irónico están siempre presentes, se advierte la intención de mostrar con claridad los contenidos. Así, información, opinión y didactismo se engarzan en estas crónicas que componen su segundo libro de 'Apuntes parlamentarios'.

En El pecado consensual se constata, además, un descenso de las crónicas centradas en la labor del Senado. La Cámara Alta, llamada irónicamente por Víctor Márquez "la Cámara de los ecos", por su repetición constante de lo ya debatido en el Congreso, pierde intensidad en sus sesiones, a pesar de las protestas de muchos senadores y de la altura intelectual de un buen número de ellos. En poco tiempo, el Senado obtiene un papel secundario en las tareas legislativas y, de forma irremediable, deja de ser objeto de atención informativa. Por ello, Víctor Márquez tiende a ocuparse en mayor medida del Congreso, aunque en ocasiones encuentre tiempo para desplazarse al $\mathrm{Pa}$ lacio de la Marina y disfrutar de la categoría retórica de los senadores, sobre todo los designados por la monarquía, como es el caso de Camilo José Cela, Julián Marías o Carlos Ollero (Cuenca Toribio, 1995: 458).

\subsection{Escaños de penitencia}

El curso político de 1979 está marcado por la doble cita electoral que afronta España a nivel estatal y municipal. Ambos comicios determinan la agenda política y provocan la transformación de las Cámaras, con nuevos diputados y senadores, tal y como testimonia Víctor Márquez en su crónica "El retorno de los culiparlantes" (31-III1979). En este trabajo, el periodista describe la realidad política española con tono lampedusiano, pues, como deja entrever, en apariencia parece que cambia todo, sin 
que realmente se modifique nada. El comienzo de esta I Legislatura, que Víctor Márquez recoge en su libro Escaños de penitencia, manifiesta esta inmovilidad en el poder, ya que UCD reedita su triunfo en las elecciones generales, y una cierta relajación con respecto a los debates constitucionales planteados en 1978, que prácticamente monopolizaron las crónicas del año anterior. Como señala Cuenca Toribio (X-1993: 89), "la temperatura del Parlamento disminuyó tras la Constitución", y ello repercutió en la actitud del cronista, que se mostró algo más "despreocupado o desinhibido" ante la actividad cotidiana de las Cámaras.

Consecuentemente, en estos textos se observa mayor espacio para la recreación literaria de los ambientes y los personajes -etopeyas- y para el análisis pormenorizado del acontecer político en general. Víctor Márquez demuestra, además, su profundo conocimiento de la situación política española vaticinando muchos de los cambios que se producirán a partir de aquel año, como, por ejemplo, la descomposición de UCD.

"Despreocupado o desinhibido un tanto de seguir el día a día del trabajo de las dos Cámaras, el cronista tendrá tiempo y ocasión para apuntar aquí alguno de los problemas suscitados en todas las democracias sobre la esencia y plasmación del principio de representatividad, para esbozar allá el papel del Senado en la joven democracia española y, en fin, para discurrir con mesura sobre una extensa porción de los asuntos más candentes de aquella hora del país. Posiblemente, es éste su libro más logrado en el fondo y la forma y el que más placenteramente escribió el autor, que desembridará su pluma para trazar etopeyas y retratos de indudable prestancia, como, entre otros, los de Tierno Galván, Fraga, Felipe González, Villar Arregui o Landelino Lavilla. [...] Merece también reseñarse en el haber del autor y en las virtudes del libro su capacidad adivinatoria, pues tanto el descalabro final de UCD como el ascenso imparable del PSOE se atalayan en muchas de sus páginas" (Cuenca Toribio, 1995: 460-461).

Algunos ejemplos de lo antedicho se encuentran en el trabajo "Fiel, pero desdichado" (17-III-1979), que más que una crónica propiamente dicha, es una semblanza de Manuel Fraga, el gran derrotado en las elecciones del 1 de marzo de 1979. En ella, Víctor Márquez se recrea en la descripción física y anímica del diputado, al que conocía bien de su etapa como profesor en Ciencias Políticas. Crónica de recreación literaria es la titulada "Los próceres en el balneario isabelino" (21-VII-1979), en la que el periodista describe el entorno de los pasillos de las Cortes. Al no poder acceder a una comisión -celebrada a puerta cerrada-, el cronista ingenia una narración casi costumbrista de las Cortes, donde aparecen personajes actuales que dialogan entre sí -los diputados Emilio Attard y Blas Piñar-, junto a otros personajes estáticos -los presidentes retratados en las galerías del Congreso-, que parecen vigilar a los vivos.

No obstante, este ánimo por describir y recrear literariamente las Cortes no es síntoma de dejadez informativa en la obra de Víctor Márquez. La actualidad y los hechos noticiosos seguirán estando presentes en sus crónicas, con un ímpetu renovado. Ocurre así, por ejemplo, en el trabajo "La guerra de las investiduras" (7-IV-1979), que fue portada de Triunfo, y que aborda la encendida discusión originada en el Congreso por la negativa de Suárez a debatir su programa político. Otros temas de gran importancia también están recogidos en Escaños de penitencia, como es el caso del Plan Ener- 
gético Nacional -"Bustélidos y solanáceos", 26-V-1979-, los debates sobre seguridad ciudadana y terrorismo -"El oficio de vivir", 2-VI-1979-, el Estado de las Autonomías -"El dos de mayo, el matrimonio y el patrimonio", 30-VI-1979-, la entrada de España en la Comunidad Económica Europea -"Europeos somos", 7-VII-1979-, el establecimiento del Tribunal Constitucional -"Reinar después de morir", 4-VIII-1979-, la Ley del divorcio -"El divorcio vendrá en octubre", 22-IX-1979-, la Ley Orgánica del Consejo General del Poder Judicial -"El consenso es cosa de dos", 17-XI-1979- o el Estatuto de los trabajadores -"Los trabajos y los días", 22-XII-1979-.

\subsection{La ruptura del consenso}

En 1980, Adolfo Suárez cumple cuatro años al frente del gobierno español, un periodo que se antojaba "eterno", según las declaraciones realizadas en el seno de su partido, pero que no tardaría en sucumbir ante las dificultades que se le presentan. Esa crisis de UCD, que se escindía poco a poco entre un sector tendente a la derecha representada por Alianza Popular y otro grupo más abierto, cercano a los postulados socialdemócratas, fue divisada meses atrás por Víctor Márquez en sus crónicas parlamentarias. Uno de los casos más significativos de esa disidencia lo protagoniza Manuel Clavero Arévalo, ministro de Administración Territorial en 1977 y de Cultura en 1979, que dimite de su cartera a comienzos de 1980, al estar en desacuerdo con la actitud tomada por su partido en materia autonómica -"El funeral autonómico", 26-I1980-. Clavero considera discriminatorio el trato que recibe Andalucía en el proceso iniciado para alcanzar el Estatuto de Autonomía. Junto a los representantes del PSOE, PSA y PCE, se manifiesta a favor de la llamada "vía rápida": la adopción del artículo 151 de la Constitución para acceder a la Autonomía. Acuciado por las aspiraciones andalucistas, el Gobierno decide finalmente convocar un referéndum en las ocho provincias andaluzas para que los ciudadanos decidieran la vía de acceso, bien a través del artículo 143 o del artículo 151, haciendo campaña a favor de la abstención.

La crisis abierta por los partidos favorables al Estatuto de Autonomía andaluz, en las mismas condiciones que las nacionalidades históricas -País Vasco y Cataluña-, acaba convirtiéndose en uno de los temas claves de los 'Apuntes parlamentarios' de Víctor Márquez, que recoge en diversos trabajos, como "El Congreso en el Apocalipsis" (23-II-1980) o "Una letra protestada" (21-VI-1980), las aspiraciones andalucistas. El periodista se compromete en cierta medida con estas pretensiones, a pesar de mantener un tono de imparcialidad en sus crónicas. Por su origen onubense y por afinidad ideológica, Víctor Márquez resaltará en sus 'Apuntes' la "cuestión andaluza”, otorgándole el protagonismo que merecía en la actualidad española.

Junto a este debate autonómico, el curso político estuvo centrado en temas ya recurrentes del parlamentarismo español, como fueron el terrorismo -ETA asesinó a 89 personas a lo largo de 1980- y la situación económica -paro e inflación-. Problemas que mermaban el liderazgo de Suárez y que animaban las opciones socialistas, sobre todo tras los buenos resultados obtenidos en las municipales.

La oposición incrementó entonces sus críticas al Ejecutivo por su actitud inmovilista y su escasa ruptura con el régimen anterior. Así lo ponen de manifiesto algunas crónicas de Víctor Márquez, como, por ejemplo, la titulada "La libertad de expresión" 
(24-V-1980), en la que el PSOE -con Alfonso Guerra a la cabeza, apodado irónicamente por el periodista como "Luzbel de Híspalis"- acusó al Gobierno de practicar la censura frente a artistas y medios de comunicación. Los procesos judiciales abiertos contra el director de El País, Juan Luis Cebrián, y la directora de cine Pilar Miró -por su película El crimen de Cuenca- sirvieron de bastiones a los socialistas para debilitar aún más a UCD. Apenas una semana después de esta sesión, el PSOE daría un golpe más certero a Suárez presentando una moción de censura, la primera de la democracia, que cogió por sorpresa a los políticos de centro-derecha. El resultado de aquella jornadas tan intensas aparecería recogido en las crónicas "La moción de censura" (31-V-1980) y "La investidura bis" (7-VI-1980), las más extensas de cuantas escribiera Víctor Márquez, dada la trascendencia de las sesiones.

La ruptura del consenso era ya un hecho palpable. El clima de acuerdo y concordia vivido apenas dos años antes, alentado por la Constitución, parecía en 1980 una reliquia de tiempos remotos. Superados ya los prejuicios y los temores hacia la izquierda, heredados de la dictadura, Felipe González se postuló entonces como un posible candidato para afrontar una nueva etapa política. Aunque la moción estaba abocada al fracaso en las votaciones, la actitud de los socialistas sirvió para poner de manifiesto la crisis del Ejecutivo y su incapacidad para resolver la situación. La capitulación de Suárez en el Congreso, sin apoyo dentro de su partido y sin el respaldo siquiera de la Corona, fue testimoniada por Víctor Márquez en sus crónicas como una de las imágenes más significativas de aquel año y, posiblemente, como una de las escenas representativas del final de un ciclo político.

No obstante, a pesar de la repercusión de aquella moción de censura, 1980 deparó otros temas parlamentarios de notable interés. La producción periodística de Víctor Márquez se centró, además, en cuestiones legislativas de gran importancia, como fueron la Ley de Reforma del Procedimiento Tributario -"La enfermedad del recuerdo", 1-III-1982-, la Ley de Centros Escolares -"Los centros del centro", 15-III-1980; "La noche de los votos largos", 22-III-1980-, la Ley Orgánica de Libertad Religiosa -"Dios es grande en el Sinaí", 5-IV-1980-, la Ley de Defensa -"La guardia civil de mañana", 19-IV-1980- o la Ley Orgánica de Financiación de las Comunidades Autónomas "Islas en el golfo", 26-IV-1980-. En total, Víctor Márquez firmó 22 crónicas parlamentarias en Triunfo a lo largo de 1980; un número inferior a lo que venía siendo habitual en él, debido al cambio en la periodicidad de la revista, que en octubre de ese año se convirtió en mensual. Como consecuencia, el periodista tuvo que readaptar sus funciones en la revista -iniciaría entonces una nueva sección, titulada 'Crónica de gentes'- y abandonar progresivamente su puesto de cronista parlamentario a partir de julio de 1980.

\subsection{Epílogo: el golpe de Estado del 23-F}

A diferencia de los anteriores cursos legislativos, en 1981 Víctor Márquez apenas pudo tratar los hechos ocurridos en el Parlamento. Los problemas económicos de Triunfo y su nueva periodicidad mensual no le permitieron continuar con sus 'Apuntes parlamentarios'. En su sección 'Crónicas de gentes'insertaría, de forma esporádica, algún comentario de agenda política, pero ya desde una perspectiva más lejana, no de 
seguimiento continuo. Aun así, a pesar de las dificultades que atravesaba su empresa, el periodista continuó asistiendo regularmente a las sesiones del Congreso, más por un interés personal que por una obligación profesional.

En 1981 se vislumbraba con claridad el cambio en la presidencia del Gobierno Suárez cedería finalmente su puesto a Calvo-Sotelo- y las Cámaras eran el espejo de esa crisis. Pero más allá de esa sucesión, Víctor Márquez advirtió intuitivamente que se podría producir un acontecimiento de mayores consecuencias. Las sospechas de una posible involución militar eran a comienzos de 1981 un secreto a voces, como al final resultó ser el golpe de Estado del 23-F.

Aquel hito, que según algunos historiadores marcó el término de la Transición española, fue precisamente la última de las crónicas parlamentarias que escribió Víctor Márquez. El trabajo, titulado "Una hora de España" (1-III-1981), acabó siendo un broche simbólico para un periodo histórico que culminaba. En esa crónica, Víctor Márquez relató paso a paso, desde una perspectiva personal, la evolución del golpe de Estado y bosquejó en su epílogo el panorama político que se avecinaba en España para los años siguientes. Un cambio que pasaba por la inevitable ascensión del PSOE al poder y por el mantenimiento de la democracia. En los continuos paréntesis de la historia de España, esta vez la suerte correría a cargo de las libertades y el derecho. Como señala Víctor Márquez al final de "Una hora de España", la moneda, el azar, ofreció la cara del Rey. A pesar del sobresalto, aquel golpe de Estado terminaría fortaleciendo el deseo de no volver a un régimen como el vivido pocos años atrás.

Aquella crónica marcó la frontera de una etapa histórica en España, pero también el final de un ciclo profesional para Víctor Márquez. Apenas seis meses después, la revista Triunfo, para la que había trabajado durante diecisiete años, cesó su actividad sin obtener el apoyo político y financiero necesario. Los 'Apuntes parlamentarios' quedarían a partir de entonces como un referente periodístico para investigadores futuros, dispuestos a reconstruir la Transición desde el punto de vista parlamentario. Así lo atestigua José Antonio Gómez Marín, quien destaca el valor de estas crónicas como ineludible fuente histórica:

"Creo que es una de las mejores fuentes que existen hoy para estudiar la política de la Transición. [...] Víctor Márquez escribió en caliente la historia de aquellos días, con un extraordinario conocimiento de las personas y de las situaciones. [...] Aparte de esto, Víctor Márquez tiene una gran capacidad de análisis. Se le escapaban muy pocas cosas de fondo, por eso fue tan pronto respetado por los propios parlamentarios, porque se dieron cuenta de que tenían un censor en la tribuna, que se iba a dar cuenta de los fallos gramaticales, léxicos o en las citas, de los solipsismos que emplean... Víctor Márquez era una 'máquina' enormemente destructiva, y en eso, los parlamentarios decidieron respetarlo y festejarlo" (Entrevista a José Antonio Gómez Marín, 2010).

\section{Conclusiones}

La crónica parlamentaria, definida como subgénero periodístico en el que se entrelazan la información y la interpretación, el hecho noticioso y el comentario, había permanecido ignorada en España durante las cuatro décadas en las que se prolonga el franquismo. La inexistencia de confrontación ideológica en las Cortes orgánicas y la censura informativa aplicada por la dictadura impidieron el desarrollo de una moda- 
lidad periodística que había gozado de notable tradición en España y cuyos orígenes se remontan a las Cortes de Cádiz, a principios del siglo XIX. Tras la muerte de Franco y el restablecimiento del Parlamento democrático en 1977, numerosos periodistas se afanaron en trasladar a los medios de comunicación lo ocurrido en las sesiones celebradas en el Congreso de los Diputados y el Senado. Entre esos cronistas se encontraba Víctor Márquez Reviriego, quien, gracias a su trabajo de documentación y al estudio de los procedimientos parlamentarios, se convertirá en unos de los periodistas especializados en temas políticos más seguidos durante el periodo de la Transición.

Sus ‘Apuntes parlamentarios', publicados en la revista Triunfo entre 1977 y 1981, contribuyeron a la renovación de la crónica de Cortes. En sus más de cien crónicas parlamentarias, Víctor Márquez se decantó por la narración clara y ordenada de los acontecimientos y los discursos pronunciados tanto en el Congreso como en el Senado. $\mathrm{Su}$ principal objetivo como cronista era el de informar sobre lo sucedido en las sesiones, sin escatimar por ello en comentarios, juicios -sobre todo, analíticos y sintéticos-, descripciones del ambiente parlamentario $\mathrm{u}$ otros recursos narrativos, como el empleo de la ironía, la metáfora, la acotación o la cita literaria o histórica.

Asimismo, estos 'Apuntes parlamentarios' representan documentos de gran valor para el estudio del devenir político en España desde la apertura de las Cortes en 1977 hasta la victoria socialista en las elecciones generales de 1982. En estas crónicas se narran e interpretan los hitos parlamentarios más importantes de la Transición española, como la aprobación de la Ley de Amnistía o la Ley de Reforma Fiscal, el consenso alcanzado en los Pactos de la Moncloa, la anulación de la pena de muerte, el debate y la votación de la Constitución, la moción de censura presentada por el PSOE contra el gobierno de Adolfo Suárez o el intento de golpe de Estado del 23 de febrero de 1981. Estos textos contienen información, comentarios, testimonios, retratos de políticos y descripciones del ambiente parlamentario, que pueden ser de notable interés para el estudio de un periodo concreto de la Historia de España.

En definitiva, las crónicas de Víctor Márquez son una fuente directa sobre la Transición, puesto que en ellas se exploran y analizan los acontecimientos en su mismo desarrollo. Constituyen una materia prima esencial para aquellos autores que deseen trasladar a trabajos de investigación lo ocurrido en España durante el paso de la dictadura a la democracia.

\section{Referencias bibliográficas}

AYALA, Francisco (1985): "Prólogo", en CAZORLA, Luis María: La oratoria parlamentaria. Madrid, Espasa-Calpe, pp. 9-16.

AZORÍN (1968): Parlamentarismo español. Barcelona, Bruguera.

BECARUD, Jean (1981): "Víctor Márquez Reviriego: Apuntes parlamentarios", en Sistema, no 41, 1 de marzo (pp. 144-149).

CARANDELL, Luis (1998): Las anécdotas del Parlamento. Se abre la sesión. Barcelona, Planeta.

CARANDELL, Luis (2000): El día más feliz de mi vida. Madrid, Espasa-Calpe. 
CARANDELL, Luis (2003): Mis picas en Flandes. Madrid, Espasa-Calpe.

CUENCA TORIBIO, José Manuel (1995): Parlamentarismo y antiparlamentarismo en España. Madrid, Servicio de Publicaciones del Congreso de los Diputados.

DURÁN LÓPEZ, Fernando (2007): "Prensa y parlamentarismo en Cádiz en el primer año de las Cortes: El Conciso (septiembre de 1810-agosto de 1811)". El Argonauta Español, http://argonauta.imageson.org/document97.html [fecha de consulta: 1 de junio de 2013].

FERNÁNDEZ FLÓREZ, Wenceslao (1950): “Acotaciones de un oyente”, en Obras completas. Madrid, Aguilar, tomo V, pp. 485-974.

FORNEAS FERNÁNDEZ, María Celia (2004): "La crónica parlamentaria (orígenes y evolución): algunas ideas", en CASALS CARRO, María Jesús (coord.): Mensajes periodísticos y sociedad del conocimiento. Libro homenaje al profesor J. $L$. Martínez Albertos. Madrid, Fragua, pp. 171-194.

FUENTES ARAGONÉS, Juan Francisco y FERNÁNDEZ SEBASTIÁN, Javier (1998): Historia del periodismo español. Madrid, Síntesis.

GIL GONZÁLEZ, Juan Carlos (2004): La crónica periodistica. Evolución, desarrollo y nueva perspectiva: viaje a la historia del periodismo interpretativo. Sevilla, Universidad de Sevilla.

GÓMEZ CANSECO, Luis (2008): "Laudatio", en MÁRQUEZ REVIRIEGO, Víctor: Acto de investidura. Doctor Honoris Causa. Huelva, Universidad de Huelva, pp. 6-15.

GÓMEZ MARÍN, José Antonio (2008): "Un birrete bien ganado", en El MundoHuelva, 3 de junio (p. 8).

HARO TECGLEN, Eduardo (1980): "Un representante de la sociedad en el Parlamento: Víctor Márquez Reviriego. El pecado consensual", en Tiempo de Historia, $\mathrm{n}^{\circ} 64,1$ de marzo (pp. 122-123).

MÁRQUEZ REVIRIEGO, Víctor (1978): La tentación canovista. Madrid, Saltés.

MÁRQUEZ REVIRIEGO, Víctor (1979): El pecado consensual. Barcelona, Argos Vergara.

MÁRQUEZ REVIRIEGO, Víctor (1981): Escaños de penitencia. Barcelona, Argos Vergara.

MÁRQUEZ REVIRIEGO, Víctor (2001): Apuntes parlamentarios. Madrid, Servicio de Publicaciones del Congreso de los Diputados.

MENÉNDEZ GIJÓN, Manuel Ángel y FERNÁNDEZ LÓPEZ-MONÍS, Carmen (2004): Los cronistas de la Constitución. Sus señorías los periodistas. Madrid, Tecnos.

NÚÑEZ LADEVÉZE, Luis (1999): "Lenguaje del político, lenguaje del informador". Estudios sobre el Mensaje Periodístico, vol. 5, pp. 111-127. Madrid, Servicio de Publicaciones de la Universidad Complutense. 
PEÑA GONZÁLEZ, José (2007): El único estadista. Una visión satírico-burlesca de don Manuel Azaña. Madrid, Fundamentos.

PÉREZ GALDÓS, Benito (1923): Política española. Madrid, Renacimiento.

PLA, Josep (2006): La Segunda República española: crónicas parlamentarias (19311936). Barcelona, Destino.

ROTKER, Susana (2005): La invención de la crónica. México D.F., Fondo de Cultura Económica.

TAMAMES, Ramón (1997): “Esforzados diputados de Víctor Márquez”, en Tribuna, 14 de abril, p. 37.

TUSELL, Javier (2004): Franquismo y Transición. Madrid, Espasa-Calpe.

UMBRAL, Francisco (1974): Crónicas antiparlamentarias. Madrid, Júcar.

UMBRAL, Francisco (1982): “La moderación”, en El País, 3 de octubre, p. 37.

VÁZQUEZ BERMÚDEZ, Miguel Ángel (2005): Periodismo de declaraciones. El pseudo-acontecimiento como base de la producción de la noticia. Los casos de El País, El Mundo y ABC. Sevilla, Universidad de Sevilla.

VICENT, Manuel (1984): Crónicas parlamentarias. Madrid, Ediciones LibertariasProdhufi. 